Supporting Information

\title{
Role of the Fraction of Blocked Nanoparticles on the Hyperthermia Efficiency of Mn-Based Ferrites at Clinically Relevant Conditions
}

V. R. R. Aquino ${ }^{\dagger}$ M. Vinícius-Araújo ${ }^{\dagger}$ Navadeep Shrivastava ${ }^{\dagger}$, M. H. Sousa ${ }^{\ddagger}$ J.A. H. Coaquira", and A. F. Bakuzis ${ }^{*, \dagger}$

${ }^{\dagger}$ Instituto de Física, Universidade Federal de Goiás, 74690-900, Goiânia-GO, Brazil. ${ }^{*}$ Faculdade de Ceilândia, Universidade de Brasília, 72220-140, Brasília-DF, Brazil

"Instituto de Física, Núcleo de Física Aplicada, Universidade de Brasília, 70910-900, Brasilia-DF, Brazil.

*E-mail: bakuzis@ufg.br 
(S1) Transmission Electron Microscopy (TEM):

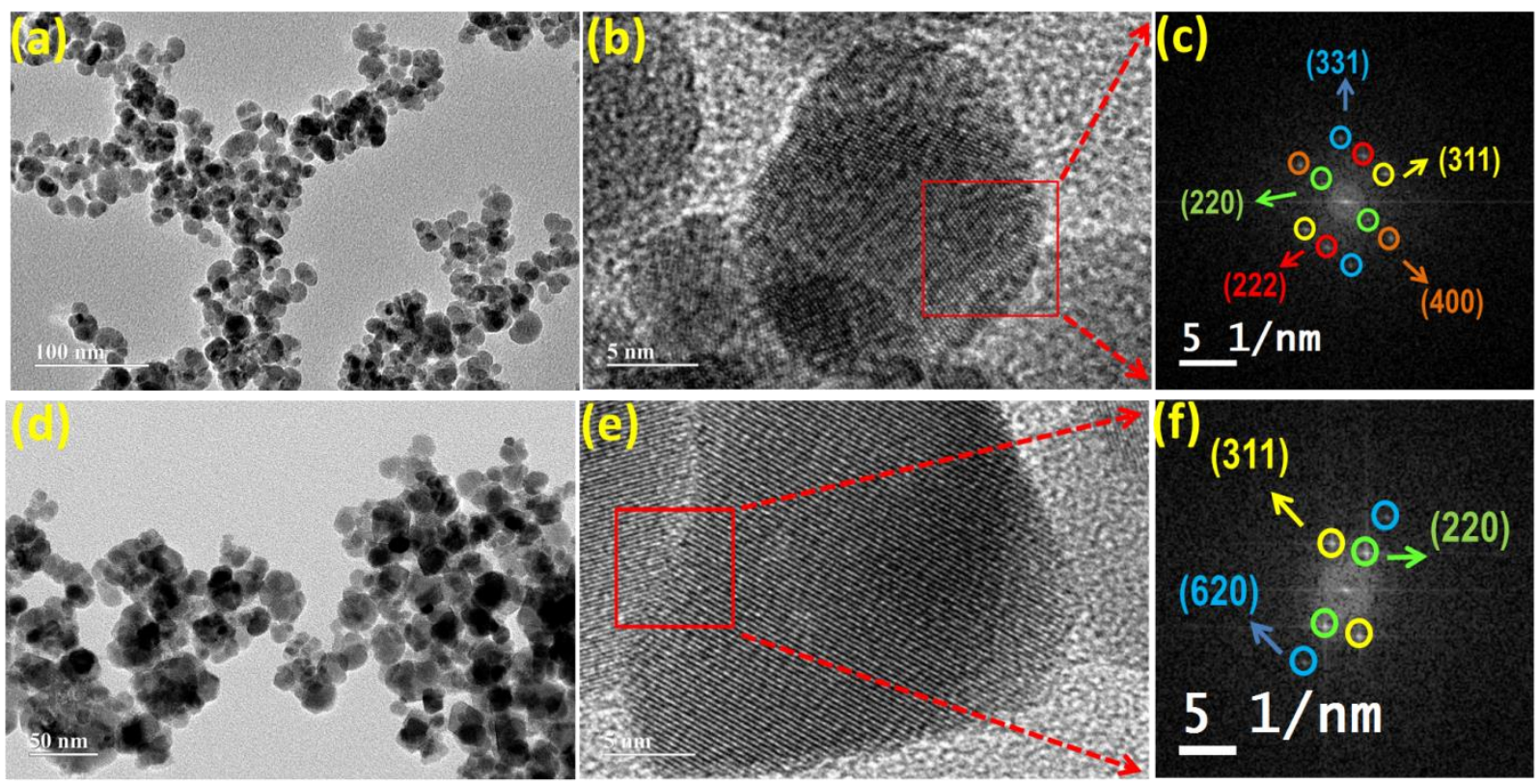

Figure S1: (a \& d)Transmission electron microscopy (TEM) images, (b \& e) high resolution TEM and respective (c \& f) Fast-Fourier transformation (FFT) analyses of selected red square region of MnZn (13 $\mathrm{nm}$, upper panel) and MnZn (18 nm, lower panel). Size distribution has been provided in the manuscript Fig. 1d.

(S2) X-ray Diffraction (XRD):

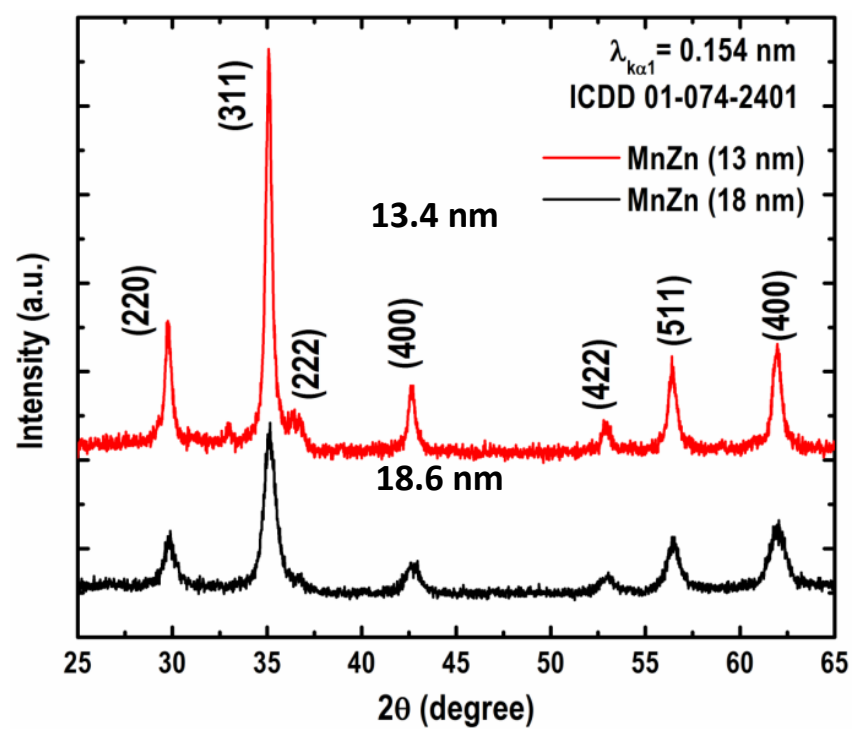

Figure S2: X-ray diffraction (XRD) of the MnZn nanoparticles of using $\mathrm{NH}_{4} \mathrm{OH}(13.4 \mathrm{~nm})$ and $\mathrm{NaOH}$ $(18.6 \mathrm{~nm})$, as a base during synthesis. 


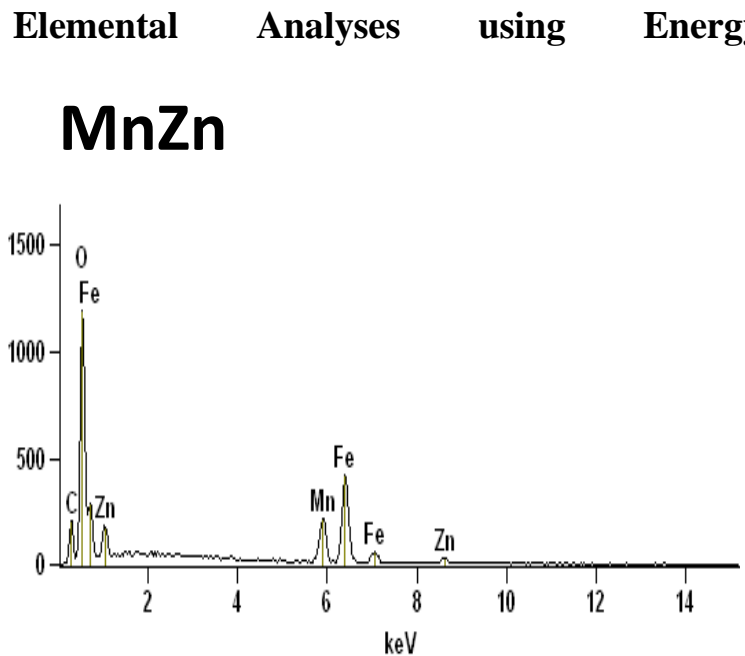

\section{$\mathrm{Mn}$}

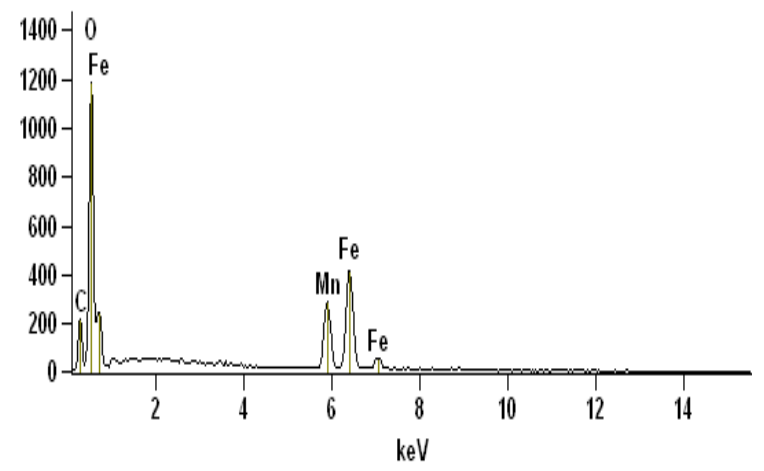

\section{$\mathrm{MnCo}$}

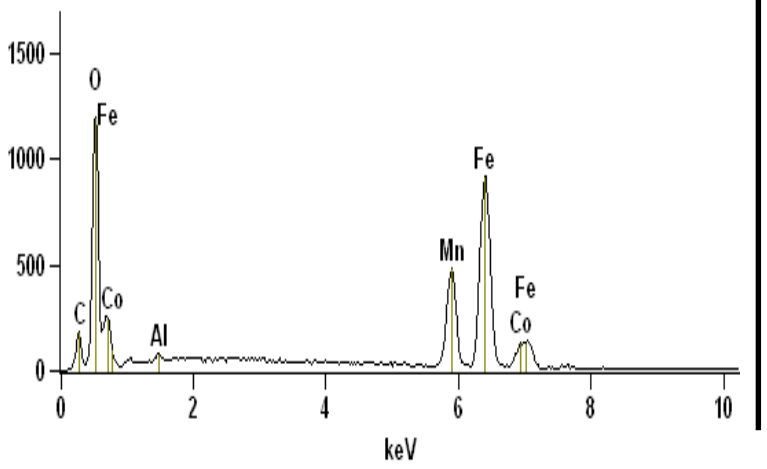

\begin{tabular}{|l|l|l|l|}
\hline Spots & $\mathrm{Mn}$ & $\mathrm{Fe}$ & $\mathrm{Zn}$ \\
\hline 1 & 27.43 & 61.29 & 11.28 \\
\hline 2 & 26.26 & 62.23 & 11.51 \\
\hline 3 & 26.51 & 60.00 & 13.49 \\
\hline 4 & 27.49 & 61.47 & 11.04 \\
\hline 5 & 26.94 & 61.25 & 11.81 \\
\hline 6 & 27.41 & 63.13 & 9.46 \\
\hline 7 & 27.44 & 63.21 & 9.35 \\
\hline 8 & 25.58 & 64.01 & 10.41 \\
\hline 9 & 26.58 & 61.96 & 11.47 \\
\hline 10 & 29.77 & 60.78 & 9.45 \\
\hline
\end{tabular}

\begin{tabular}{|c|c|c|c|}
\hline \multicolumn{2}{|l|}{ Spots } & $\mathrm{Mn}$ & $\mathrm{Fe}$ \\
\hline \multicolumn{2}{|l|}{1} & 36.49 & 61.50 \\
\hline \multicolumn{2}{|l|}{2} & 37.95 & 62.05 \\
\hline \multicolumn{2}{|l|}{3} & 36.74 & 61.51 \\
\hline \multicolumn{2}{|l|}{4} & 35.25 & 64.75 \\
\hline \multicolumn{2}{|l|}{5} & 38.93 & 61.07 \\
\hline \multicolumn{2}{|l|}{$\overline{6}$} & 36.77 & 63.23 \\
\hline \multicolumn{2}{|l|}{$\overline{7}$} & 37.77 & 62.23 \\
\hline \multicolumn{2}{|l|}{8} & 37.14 & 62.86 \\
\hline \multicolumn{2}{|l|}{$\overline{9}$} & 37.01 & 62.99 \\
\hline 10 & \multicolumn{2}{|c|}{36.68} & 63.32 \\
\hline Spot & $M n$ & $\mathrm{Fe}$ & Co \\
\hline 1 & 27.34 & 66.00 & 6.66 \\
\hline 2 & 29.22 & 64.61 & 6.17 \\
\hline 3 & 28.02 & 64.35 & 7.63 \\
\hline 4 & 28.47 & 65.42 & 6.12 \\
\hline 5 & 28.33 & 63.85 & 7.81 \\
\hline 6 & 28.53 & 64.06 & 7.41 \\
\hline 7 & 28.83 & 63.94 & 7.23 \\
\hline 8 & 27.98 & 64.07 & 7.95 \\
\hline 9 & 28.39 & 63.73 & 7.88 \\
\hline 10 & 28.03 & 66.17 & 5.80 \\
\hline
\end{tabular}

Figure S3: Left vertical panel shows the existence of $\mathrm{Zn}, \mathrm{Mn}, \mathrm{Co}$, and $\mathrm{Fe}, \mathrm{O}$ elements and right vertical panel shows the quantitative amounts of $\mathrm{Zn}, \mathrm{Mn}, \mathrm{Co}$, and Fe in respective $\mathrm{MnZn}, \mathrm{Mn}, \mathrm{MnZn}$ samples with $\sim 10 \mathrm{~nm}$ sizes, obtained by SEM-EDS measurements at 10 spots. 


\section{(S4) Magnetic Hyperthermia for ZnMn (13 nm and $18 \mathrm{~nm})$ Nanoparticles}

(at $\mathrm{f}=522 \mathrm{kHz}$, and $\varphi=0.03(3 \%))$ :
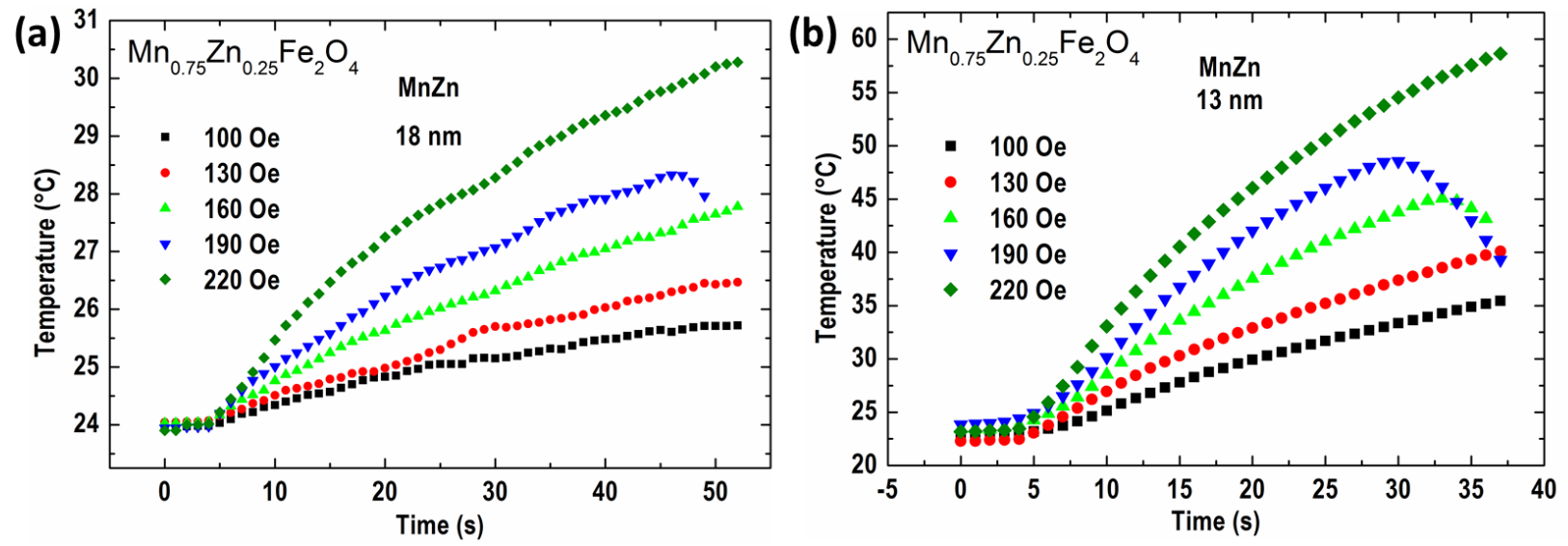

Figure S4: Magnetic hyperthermia (temperature versus time) experiments for large sizes of MnZn (18 nm in (a) and $13 \mathrm{~nm}$ in (b)) at concentration $\varphi=0.03(3 \%)$ at $522 \mathrm{kHz}$, which shows the lower heating profile in comparison of $10 \mathrm{~nm} \mathrm{MnZn} \mathrm{nanoparticles.}$

\section{(S5) SLP calculated by different methods}

It is important to note that the initial slope method considers the slope for the $\mathrm{T}$ vs $\mathrm{t}$ curves at the beginning i.e. $\left(\frac{\mathrm{d} T}{d t}\right)_{t \rightarrow 0}$, where losses are negligible. Hence the SLP can be defined as:

$S L P=\frac{C}{m} \cdot\left(\frac{\mathrm{d} T}{d t}\right)_{t \rightarrow 0}$, where $C$ is the heat capacity and $m$ is the mass of magnetic nanoparticles.

The Box Lucas method is based on the assumption where the curves $\mathrm{T} \times \mathrm{t}$ should follow equation $T=$ $T_{0}+\Delta T_{\max }\left(1-e^{-t / \tau}\right)$, where $T_{0}$ is the initial temperature, $\Delta T_{\max }$ is the maximum temperature increment and $\tau$ is the relaxation time. In this case the SLP is given by

$$
S L P=\frac{C}{m} \cdot \frac{\Delta T_{\max }}{\tau}
$$

The Maximum Slope method uses the maximum slope calculated on each point of the $\mathrm{T} x \mathrm{t}$ curves, i.e. $\left(\frac{\mathrm{d} T}{d t}\right)_{\max }$ at every point, therefore heating efficiency is given by

$$
S L P=\frac{C}{m} \cdot\left(\frac{\mathrm{d} T}{d t}\right)_{\max }
$$

Figure S5 shows the SLP versus field calculated by different methods of the samples MnZn, Mn and MnCo $10 \mathrm{~nm}$. 


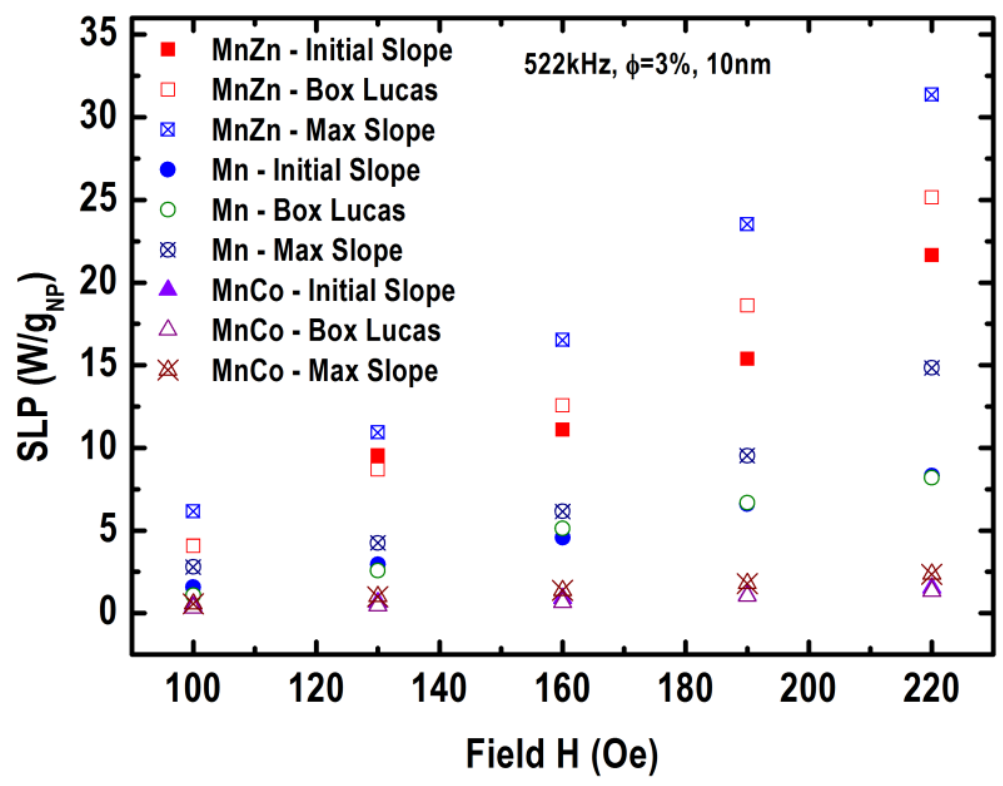

Figure S5: SLP versus field calculated by different methods of $\mathrm{MnZn}, \mathrm{Mn}$ and $\mathrm{MnCo} 10 \mathrm{~nm}$ at concentration $\varphi=0.03$ (or $3 \%$ ) at $522 \mathrm{kHz}$. 